\title{
Effects of guided bone regeneration with non-resorbable and bioabsorbable barrier membranes on osseointegration around hydroxyapatite-coated and uncoated threaded titanium dental implants placed into a surgically-created dehiscence type defect in rabbit tibia: a pilot study
}

\author{
Koichi Ito, Yutaka Yamada, Ryo Ishigaki, Koichi Nanba, \\ Tetsuya Nishida and Shuichi Sato \\ Department of Periodontology, Nihon University School of Dentistry, Tokyo 101-8310 \\ (Received 30 January and accepted 9 March 2001)
}

\begin{abstract}
The purpose of this study was to evaluate the effects of guided bone regeneration (GBR) with either a non-resorbable (ePTFE) or bioabsorbable barrier membrane (RSLT) on osseointegration and extent of bone formation around hydroxyapatite-coated (HA) and uncoated threaded titanium (Ti) dental implants placed into surgically-created dehiscence type defects in rabbit tibia. A dehiscence type bone defect, approximately $3 \mathrm{~mm}$ in width and height was surgically created on the outer surface of the bone in each tibia of 9 rabbits. For the conventional group, either a $\mathrm{HA}$ or a Ti implant was then placed at this site. After the same procedure was performed as in the conventional group, the implant site of the GBR group was covered with either an ePTFE or a RSLT. After 4 months, the rabbits were sacrificed. Specimens were prepared and examined histometrically. It was found that the mean percentage of osseointegration tended to increase in $\mathrm{HA}$ compared to $\mathrm{Ti}$ implants, both with and without membranes. There was a tendency that the extent of newly regenerated bone was higher in the GBR group than that in the conventional group. (J. Oral Sci. 43, $61-67,2001$ )
\end{abstract}

Correspondence to Dr. Koichi Ito, Department of Periodontology, Nihon University School of Dentistry, 1-8-13 Kanda-Surugadai, Chiyoda-ku, Tokyo 101-8310, Japan

Phone: +81-3-3219-8097 Fax: +81-3-3219-8349

E-mail address: ito-k@dent.nihon-u.ac.jp
Key word: bone regeneration; barrier membranes; dental implants; dehiscence type defects.

\section{Introduction}

In the past 10 years, the use of barrier membranes has significantly changed implant dentistry. This principle, often termed guided bone regeneration (GBR), is used to optimize bone regeneration in areas with localized bone defects in the alveolar process. Barrier membranes have been used in various indications to regenerate bone defects in implant patients. Several factors are essential for the achievement of predictable results with barrier membranes. One of them is the creation and maintenance of a secluded space. This is particularly important in so-called "nonspace-making defects", such as dehiscence type bone defect, where the membrane is not sufficiently supported by local bone walls. An expanded polytetrafluoroethylene membrane (ePTFE) is widely used as a non-resorbable, bio-inert membrane with excellent scientific documentation (1).

However, clinical and experimental studies have shown that standard ePTFE is susceptible to partial or complete membrane collapse (2-5). Recently, bioabsorbable membranes have been introduced for periodontal indications. There are two main types of bioabsorbable membranes: 1) synthetic polymers such as polylactic acid and polyglycolic acid, and 2) xenographic collagen (1). These materials have been tested in a number of 
experimental studies for the regeneration of bone defects $(6,7)$. In order to avoid exposure and the inconvenience of removal, most research has been directed towards testing bioabsorbable membranes $(8,9)$.

However, a major question with these bioabsorbable membranes, especially with GBR, is how long the integrity of the membrane lasts. As noted above, space maintenance is a crucial aspect for successful GBR. Studies must demonstrate if bioabsorbable membranes have the same potential and efficacy for successful bone regeneration as do the ePTFE.

The purpose of this pilot study was to evaluate the healing events and compare the effects of GBR with either a non-resorbable or a bioabsorbable barrier membrane on osseointegration and extent of bone formation around hydroxyapatite-coated and uncoated threaded titanium dental implants placed into a surgically-created dehiscence type defect in rabbit tibia.

\section{Materials and Methods}

Membrane characteristics

Two different types of barrier membranes were used and compared as follows:

1) non-resorbable barrier membrane (ePTFE: Gore-Tex membrane GT4, W.L. Gore and Associates, Inc., Flagstaff, AZ, USA); 2) bioabsorbable barrier membrane (RSLT: Resolut R4, W.L. Gore and Associates, Inc., Flagstaff, AZ, USA).

\section{Dental implant fixture characteristics}

Two different types of dental implants were used and compared as follows:

1) hydroxyapatite-coated threaded titanium dental implant (HA: hex lock, $3.25 \times 8 \mathrm{~mm}$, Steri-Oss inc., Yorba Linda, CA, USA); 2) uncoated threaded titanium dental implant (Ti: hex lock, $3.25 \times 8 \mathrm{~mm}$, Steri-Oss inc., Yorba Linda, CA, USA).

\section{Animals}

This study was conducted according to the guidelines specified by the Nihon University School of Dentistry Animal Committee. Nine adult male Japanese white rabbits (weighing 2.8 to $3.2 \mathrm{~kg}$ ) were used in this study. Prior to surgery, all animals were kept in standard cages and fed with a standard laboratory diet and water.

\section{Surgical procedure}

The hind legs of each rabbit were shaved and washed with $70 \%$ ethanol. The medial surfaces of both tibia were exposed via a skin incision and careful subperiosteal dissection. A conventional implant site was prepared in the tibial methaphysis in accordance with the established technique outlined in the manufacturer's technical brochure. A dehiscence type bone defect (approximately $3 \times 3 \mathrm{~mm}$ ) was surgically-created to remove the outer bone of the implant site. Next, either a HA or a Ti was placed at this site (conventional group). After the same procedure was performed as in the conventional group, the implant site was covered with either an ePTFE or a RSLT (GBR group).

A total of 18 implants sites from 9 rabbits were prepared and divided into 2 main groups, conventional and GBR groups. Furthermore, the conventional and GBR groups were divided into the following subgroups as follows: 1 ) conventional group; (1) HA; (2) Ti; and 2) GBR group; (1) HA + ePTFE; (2) Ti + ePTFE; (3) HA + RSLT and (4) Ti + RSLT.

The surgery was performed under clean conditions and with generous irrigation using sterile saline. Thereafter, periosteum muscle and skin were replaced and sutured with a bioabsorbable suture (5-0 Plain Gut, Ethicon, Inc., Somerville, NJ, USA). The rabbits were administered intramuscular injections of penicillin $(2,500,000 \mathrm{IU} / 5 \mathrm{ml}$; $0.1 \mathrm{ml} / \mathrm{kg}$ ) postoperatively.

\section{Histological procedure}

After healing for 4 months, the rabbits were euthanized with an overdose of pentobarbital. The implants with surrounding tissues were dissected out, fixed with $10 \%$ neutral buffered formalin, dehydrated and embedded in polyester resin (Rigolac-2004, Rigolac-70F, Nisshin EM Co., Ltd., Tokyo, Japan). One cross-sectional undecalicfied ground section (approximately $200 \mu \mathrm{m}$ thick), from the central part of the implant and encompassing the entire bone defect/membrane and surrounding tissue of each specimen, was prepared using a slow-speed diamond saw (Micro cutter, MC-201, Maruto, Tokyo, Japan). The sections were mounted on acrylic glass slabs, ground and polished to a final thickness of $50 \mu \mathrm{m}$, stained with basic fuchsin and methylene blue and examined under a light microscope (Olympus AH-2, Tokyo, Japan).

Histological examination, photography and morphometric measurements of the sections were performed using a microscope equipped with a morphometric system connected to a personal computer (Macintosh Performa 558, Apple Computer Inc., Cupertino, CA, USA). The histomorphometric measurements of the central section obtained from each specimen were recorded using a computerized image analysis system. Slides taken at $\times 20$ magnification were digitized using a solid-state $35-\mathrm{mm}$ slide scanner and a CCD linear photo diode array interfaced with a computer. The measurements were extracted from the digital images using an interactive image processing soft 
ware package (Adobe Photoshop 2.5 J, Apple Computer Inc., Cupertino, CA, USA).

The percentage of osseointegration between bone and implant surface was calculated at a $3 \mathrm{~mm}$ length apical to the inferior border of the periodontal collar of each implant (Fig. 1). We measured the length of the implant facing the surrounding bone (A) and the length of surface border where the bone directly contacted the implant $\left(B=b_{1}+\right.$ $\left.b_{2}+b_{3}+\cdots \cdots \cdots . . ..\right)$. The percentage of osseointegration between bone and implant surface was calculated as follows: the percentage of osseointegration $(\%)=(\mathrm{B}) /(\mathrm{A})$ $\times 100(10)$.

In addition, the height $(\mathrm{H})$ and width (W1 and W2) of regenerated bone in each group were measured as shown in Fig.1.

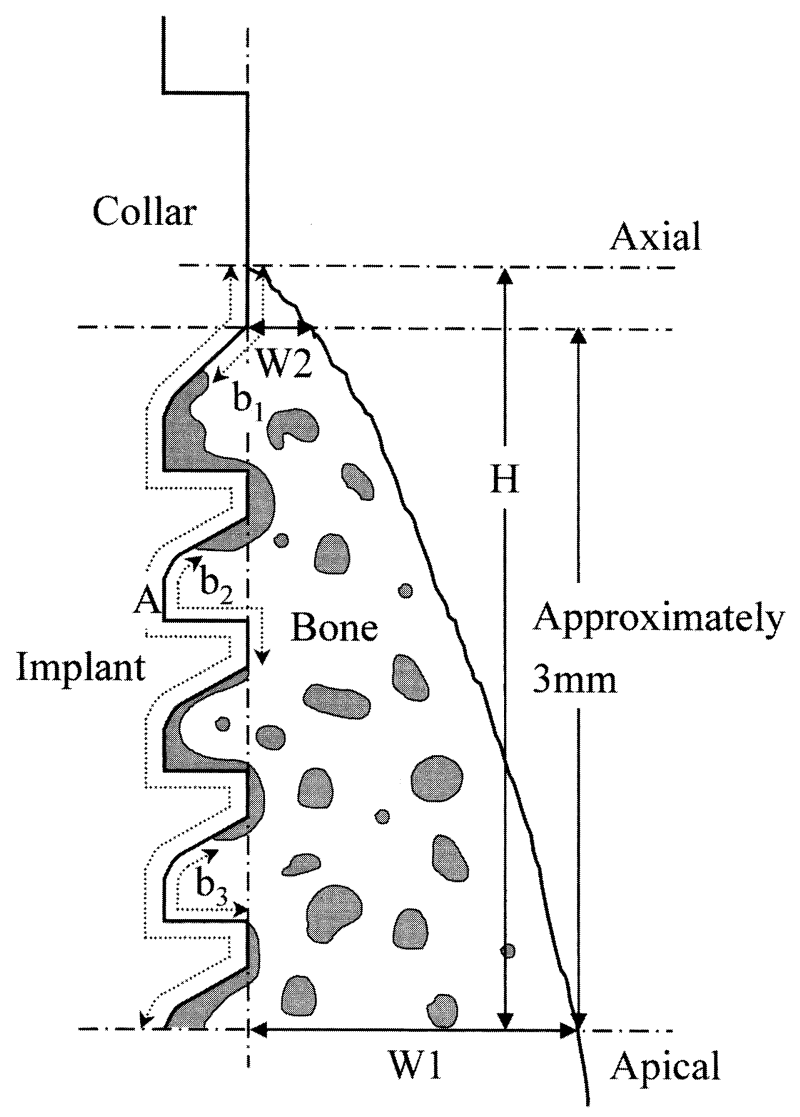

Fig. 1 A schema of an area selected for analysis of osseointegration. " $\mathrm{A}$ " is the length of the implant facing the surrounding bone. "B= $\mathrm{b}_{1}+\mathrm{b}_{2}+\mathrm{b}_{3}+\cdots \cdot . "$ is the surface border where the bone directly contacted the implant. " $\mathrm{H}$ " is the height of the newly regenerated bone from the inferior border of the surgically-created bone defect. "W1" is the width at the inferior border of the bone defect. "W2" is the width at the inferior border of the implant collar.

\section{Clinical findings}

\section{Results}

Healing generally progressed uneventfully in all groups. No clinical findings of adverse reactions or inflammation could be observed around the implants. However, three legs of three rabbits were broken and two rabbits died before the end of the experiment. No complications were found among the other animals. Eleven implant sites were clinically stable: HA (3); Ti (2); HA + ePTFE (1); Ti + ePTFE (1); HA + RSLT (2) and Ti + RSLT (2).

\section{Light microscopy observations}

For all groups, focal areas of osseointegration were generally seen on both the HA and Ti covered with and without both membranes (Figs. 2-5). The resident bone appeared structurally normal around the dental implants. Osseointegration, without signs of infection or fibrous connective tissue infiltration, was observed for both implant configurations. However, the mean percentage of osseointegration tended to increase in HA compared to $\mathrm{Ti}$ with and without membranes as follows: $\mathrm{HA}+\mathrm{GBR}>\mathrm{HA}>\mathrm{Ti}+\mathrm{GBR}>\mathrm{Ti}$ (Fig. 6). There was a tendency that the extent of newly regenerated bone was higher in the GBR group than that in the conventional group (Fig. 7).

\section{Discussion}

This pilot study evaluated the percentage of osseointegration and extent of newly regenerated bone over a 4-month healing interval for HA or Ti placed into the surgically-created dehiscence type defect covered with or without either an EPTFE or a RSLT in rabbit tibia. The results demonstrated that for the HA, there was a tendency for an increase in the percentage of osseointegration relative to the Ti. There are several experimental studies demonstrating a more rapid and favorable response to HA compared to the $\mathrm{Ti}$ (11-14). These investigators stated that while there was abundant documentation of the advantage of HA coatings for bone contact for cylindrical implants, their data suggested that this was not as certain for screw-shaped implants. We also demonstrated that the screw-shaped HA consistently showed a greater amount of osseointegration either in the conventional site or in the intrabony type of defect region with and without ePTFE (15).

In addition, for the GBR group there was a tendency for the height of the newly regenerated bone to increase relative to the conventional group. In clinical situations, dehiscence defects associated with dental implants were often observed at the thin alveolar ridge. One prerequisite 


$$
\mathbb{1 1}
$$


for successful anchorage of dental implants is that a sufficient volume of healthy bone is available. It has been suggested that at least $1 \mathrm{~mm}$ of supporting bone should be present at the lingual/palatal and facial aspects of the dental implant to achieve good prognosis (16). However, the results of this study showed that the width of the newly regenerated bone at the reference site (W2) was less than $1 \mathrm{~mm}$ (Fig. 7).

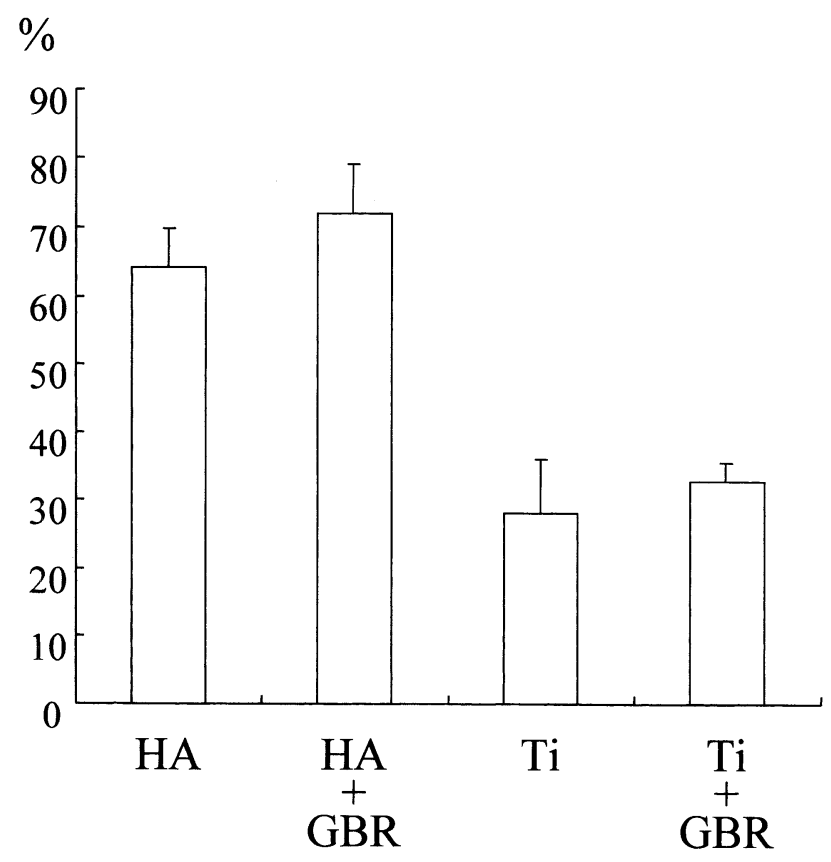

Fig. 6 Mean percentage of osseointegration by implant and treatment type for each group.

$\mathrm{mm}$

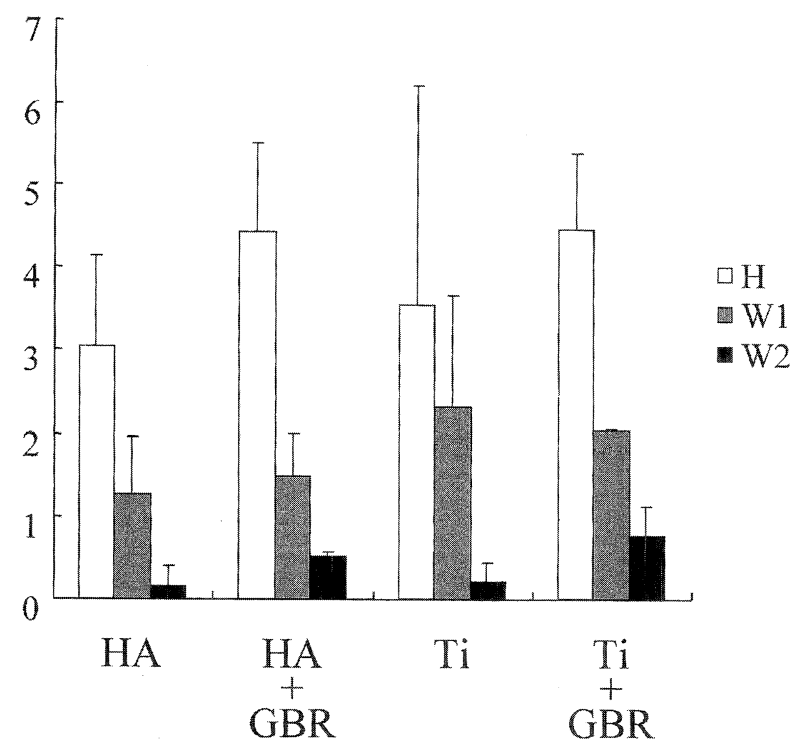

Fig. 7 Mean height and width of the newly regenerated bone at the reference sites.
One therapy of choice in situations with insufficient bone volume is the use of barrier membranes for GBR (17). The placement of a barrier membrane for the GBR creates an isolated space for a blood clot to serve as a matrix for alveolar bone regeneration (5). The dehiscence defects are referred to as "non-space-making defects" and adjunctive measures have been suggested to support or tent the barrier membrane. These measures provide a space for bone regeneration to occur, and include placement of autograft bone, bone derivatives, or fixation screws or pins $(2,18$ 20).

At present, the best-documented membrane for GBR is ePTFE. However, one major problem associated with the use of ePTFE has been the high rate of complications, such as exposure to the oral environment to subsequently developing infection. Impaired treatment outcomes, lack of predictability of the therapy, and resorption of the already regenerated bone, or even loss of parts of the preexisting bone, have been reported as sequelae of these complications $(2,18)$. Several bioabsorbable membranes used for bone regeneration were tested in some studies $(8,21,22)$. The most important drawback of these membranes seems to be the lack of stiffness.

The problem of minimal bone-to-implant contact following regeneration has been previously reported. Becker (23) reported only minimal contact in an animal experimental study, where dehiscence defects were augmented with ePTFE alone. A human pilot study similarly reported excellent bone regeneration into the dehiscence defects, but only minimal new bone-to-implant contacts (24). However, Hämmerle et al. (25) have demonstrated high bone-to-implant contact fractions as a result of GBR in the treatment of dehiscence defects. According to Cho et al. (26), GBR results in rapid, clinically-relevant bone closure of dental implant dehiscent defects. Adjunctive implantation of xenogenic freezedried demineralized bone matrix does not appear to significantly improve the healing response in the dog model. Lundgren et al. (27) observed that the coverage of autologous bone grafts with a bioresorbable membrane (Guidor) resulted in a large volume of augmented bone, as compared with the use of bone grafts not covered with a barrier.

Bioabsorabable materials used for GBR devices fall into two broad categories: natural products and synthetic materials. RSLT is a composite consisting of an occlusive membrane of glycolide and lactide copolymer and a porous web structure of bonded polyglycolide fiber (28). Several studies demonstrated that RSLT facilitated GTR wound healing in intrabony defects and class II furcation involvements. Within the body, the resorption of these 
materials is minimal for approximately 4 to 6 weeks and is essentially completed by 5 to 8 months (8). Hürzeler et al. (29) reported that the RSLT had completely resorbed by the 5-month examination period in monkeys. In the current rabbit study, the RSLT was completely resorbed by the 4-month examination period.

In conclusion, there was a tendency that the GBR, using either ePTFE or RSLT, enhanced the percentage of osseointegration and increase of volume in newly regenerated bone around the $\mathrm{HA}$ and Ti placed into surgically-created dehiscence defects in rabbit tibia. Furthermore, the HA, with or without membranes, consistently showed greater amounts of osseointegration in this limited pilot study. However, there was not enough width $(<1 \mathrm{~mm})$ of the newly regenerated bone at the collar area of both types of dental implants fixtures in all groups. Therefore, in non-space-making defects, such as buccal dehiscence defects, adjunctive measures have been suggested to support or tent the barrier membrane to provide a space for bone regeneration to occur. These measures include placement of autograft bone, bone derivatives and substitutes, or fixation screws or pins, with or without bone materials.

\section{Acknowledgments}

This study was supported by Grant in Sato Fund, Nihon University School of Dentistry in 1997.

\section{References}

1. Hardwick, R., Scantlebury, T.V., Sanchez, R., Whitley, N. and Ambruster, J. (1994) Membrane design criteria for guided bone regeneration of the alveolar ridge. In Guided bone regeneration in implant dentistry, Buser, D., Dahlin, C. and Schenk, R.K. eds., Quintessence Publishing, Chicago, 101136

2. Buser, D., Bragger, U., Lang, N.P. and Nyman, S. (1990) Regeneration and enlargement of jaw bone using guided tissue regeneration. Clin. Oral Implants Res. 1, 22-32

3. Schenk, R.K., Buser, D., Hardwick, W.R. and Dahlin, C. (1994) Healing pattern of bone regeneration in membrane-protected defects: a histologic study in the canine mandible. Int. J. Oral Maxillofac. Implants 9, 13-29

4. Buser, D., Dula, K., Belser, U., Hirt, H.P. and Berthold, H. (1993) Localized ridge augmentation using guided bone regeneration. 1. Surgical procedure in the maxilla. Int. J. Periodontics Restorative Dent.13, 29-45

5. Buser, D., Dula, K., Hirt, H.P. and Berthold, H.
(1994) Localized ridge augmentation using guided bone regeneration. In Guided bone regeneration in implant dentistry, Buser, D., Dahlin, C. and Schenk, R.K. eds., Quintessence Publishing, Chicago, 189233

6. Aaboe, M., Pinholt, E.M., Hjørting-Hansen, E., Solheim, E. and PrÊtorius, F. (1993) Guided tissue regeneration using degradable and nondegradable membranes in rabbit tibia. Clin. Oral Implants Res. 4, 172-176

7. Sevor, J.J., Meffert, R.M. and Cassingham, R.J. (1993) Regeneration of dehisced alveolar bone adjacent to endosseous dental implants utilizing a resorbable collagen membrane: clinical and histologic results. Int. J. Periodontics Restorative Dent. 13, 71-83

8. Caffesse, R.G., Nasjleti, C.E., Morrison, E.C. and Sanchez, R. (1994) Guided tissue regeneration: comparison of bioabsorbable and non-bioabsorbable membranes. Histologic and histometric study in dogs. J. Periodontol. 65, 583-591

9. Greenstein, G. and Caton, J.G. (1993) Biodegradable barriers and guided tissue regeneration. Periodontol.2000 1, 36-45

10. Takeshita, F., Matsushita, Y., Ayukawa, Y. and Suetsugu, T. (1996) Fractures of hydroxyapatitecoated blade implants connected with natural teeth. A histological study using SEM, light microscopy, and an image processing system. J. Periodontol. 67, 86-92.

11. Kohri, M., Cooper, E.P., Ferracane, J.L. and Waite, D.F. (1990) Comparative study of hydroxyapatite and titanium dental implants in dogs. J. Oral Maxillofac. Surg. 48, 1265-1273

12. Pilliar, R.M., Deporter, D.A., Watson, P.A., Pharoah, M., Chipman, M., Valiquette, N., Carter, S. and De Groot, K. (1991) The effect of partial coating with hydroxyapatite on bone remodeling in relation to porous-coated titanium-alloy dental implants in the dog. J. Dent. Res. 70, 1338-1345

13. Jansen, J.A., van de Waerden, J.P., Wolke, J.G. and de Groot, K. (1991) Histologic evaluation of the osseous adaptation to titanium and hydroxyapatitecoated titanium implants. J. Biomed. Mater. Res. 25,973-989

14. Stentz, W.C., Mealey, B.L., Gunsolley, J.C. and Waldrop, T.C. (1997) Effects of guided bone regeneration around commercially pure titanium and hydroxyapatite-coated dental implants. II. Histologic analysis. J. Periodontol. 68, 933-949

15. Ito, K., Nanba, K., Nishida, T., Sato, H. and Murai, 
S. (1998) Comparison of osseointegration between hydroxyapatite-coated and uncoated threaded titanium dental implants placed into surgicallycreated bone defect in rabbit tibia. J. Oral Sci. 40, 37-41

16. Lekholm, U., Adell, R., Lindhe, J., Brånemark, P.I., Eriksson, B., Rockler, B., Lindvall, A.M. and Yoneyama, T. (1986) Marginal tissue reactions at osseointegrated titanium fixtures. (II) A crosssectional retrospective study. Int. J. Oral Maxillofac. Surg. 15,53-61

17. Nyman, S.R. and Lang, N.P. (1994) Guided tissue regeneration and dental implants. Periodontol. 2000 4, 109-118

18. Jovanovic, S.A., Spiekermann, H. and Richter, E.J. (1992) Bone regeneration around titanium dental implants in dehisced defect sites: a clinical study. Int. J. Oral Maxillofac. Implants. 7, 233-245

19. Nevins, M. and Mellonig, J.T. (1992) Enhancement of the damaged edentulous ridge to receive dental implants: a combination of allograft and the GORETEX membrane. Int. J. Periodontics Restorative Dent. 12, 96-111

20. Rominger, J.W. and Triplett, R.G. (1994) The use of guided tissue regeneration to improve implant osseointegration. J. Oral Maxillofac Surg. 52, 106112

21. Simion, M., Scarano, A., Gionso, L. and Piattelli, A. (1996) Guided bone regeneration using resorbable and nonresorbable membranes: a comparative histologic study in humans. Int. J. Oral Maxillofac. Implants 11, 735-742

22. Simion, M., Misitano, U., Gionso, L. and Salvato, A. (1997) Treatment of dehiscences and fenestrations around dental implants using resorbable and nonresorbable membranes associated with bone autografts: a comparative clinical study. Int. J. Oral Maxillofac. Implants 12, 159-167
23. Becker, W., Schenk, R., Higuchi, K., Lekholm, U. and Becker, B.E. (1995) Variations in bone regeneration adjacent to implants augmented with barrier membranes alone or with demineralized freeze-dried bone or autologous grafts: a study in dogs. Int. J. Oral Maxillofac. Implants 10, 143-154

24. Palmer, R,M,, Floyd, P.D., Palmer, P.J., Smith, B.J., Johansson, C.B. and Albrektsson, T. (1994) Healing of implant dehiscence defects with and without expanded polytetrafluoroethylene membranes: a controlled clinical and histological study. Clin. Oral Implants Res. 5, 98-104

25. Hämmerle, C.H.F., Chiantella, G.C., Karring, T. and Lang, N.P. (1998) The effect of a deproteinized bovine bone mineral on bone regeneration around titanium dental implants. Clin. Oral Implants Res. 9, 151-162

26. Cho, K-S., Choi, S-H., Han, K-H,, Chai, J-K., Wikesjö, U.M.E. and Kim, C-K. (1998) Alveolar bone formation at dental implant dehiscence defects following guided bone regeneration and xenogenic freeze-dried demineralized bone matrix. Clin. Oral Implants Res. 9, 419-428

27. Lundgren, A.K., Sennerby, L., Lundgren, D., Taylor, A., Gottlow, J. and Nyman, S. (1997) Bone augmentation at titanium implants using autologous bone grafts and a bioresorbable barrier. An experimental study in the rabbit tibia. Clin. Oral Implants Res. 8, 82-89

28. Tatakis, D.N., Promsudthi, A. and Wikesjö, U.M.E. (1999) Devices for periodontal regeneration. Periodontol. 2000 19, 59-73

29. Hürzeler, M.B., Quinones, C.R., Caffesse, R.G., Schupbach, P. and Morrison, E.C. (1997) Guided periodontal tissue regeneration in interproximal intrabony defects following treatment with a synthetic bioabsorbable barrier. J. Periodontol. 68, 489-497 